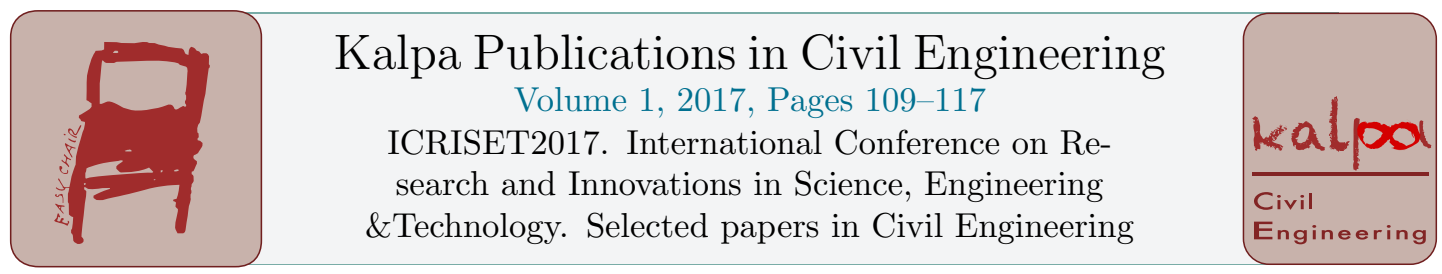

\title{
Seismic Protection of Symmetric Building Equipped with Water Sloshing Damper
}

\author{
C. M. Asodariya ${ }^{1}$ and C.C. Patel $^{2}$ \\ ${ }^{1}$ P.G. Student, Department of civil engineering, Marwadi Education Foundation Group of \\ Institution, Rajkot, India - 360003 \\ ${ }^{2}$ Professor, Department of civil engineering, Marwadi Education Foundation Group of Institution, \\ Rajkot, India - 360003. \\ chiragasodariya27@gmail.com, ccstructegmail.com
}

\begin{abstract}
Now a days, in densely populated areas it is desired to have a taller structures which are light in weight and also very flexible. But in real cases the weight is higher thus they are more vulnerable to the environmental load and may lead to collapse of the structure and generate the serviceability problems. Different types of approaches are available to minimize the response of the structure, from the different approaches concept of Tuned Liquid Damper (TLD) is a newer one to reduce the response of the structure. In the TLD, liquid is filled in the tank which reduces the response of the structure using action of liquid sloshing. These TLD dampers are economical as well as less serviceability cost effective passive response reducers, which are being used in the structure having less stiffness and having a low value of damping of structure. In this study, considering Tuned mass damper (TMD) analogy the response of the Single Degree of Freedom (SDOF) system with nonlinear behavior of Tuned sloshing water damper (TSWD was investigated. Four different earthquake ground motion time history like Imperial valley (1940), Loma prieta (1989), Northridge (1995), Kobe (1994) has been used to investigate the behavior of SDOF structure with water sloshing damper. A numerical study was carried out with different important parameters such as mass ratio, and frequency ratio the results showed that there was a reduction in the acceleration response of the structure up to $33 \%$ by using different mass ratio. It is also observed that $4 \%$ mass ratio is most effective for the acceleration response reduction of the structure.
\end{abstract}

\section{Introduction}

Latest civil engineering tall structures are flexible, weakly damped and light weight. Tuned liquid dampers are used to reduce the structural response in such structures. A TLD is either stiffer cylindrical or rectangular liquid tank which are fixed at the top of the SDOF system. These dampers are configure 
as either in huge tank or mixture of the small tanks. The liquid, in general, is water. There were many experimental and numerical research works [6][11][2][4][5] in the past years carried out to illustrate potential of TLD when used as a response reduction device for the system experiencing both broad band as well as harmonic base excitation. The shallow water wave theory has been used incorporating effect of braking of waves which ultimately represents a rectangular TLD as nonlinear model (Sun et al. (1992)). Banerji et al. (2000) used the formulation suggested by [10] and [3] experimentally found inconsistency in the results which was obtained by using the formulation given by sun et al. This was happened due to the lacking of actual prediction of the water surface cause by braking of the waves in the shallow water model. For the solution of this problem Samanta and Banerji (2006)[8] used a various shallow water theory and two numerical schemes, the Lax finite difference method and the random choice method, The response of SDOF system equipped with TLD subjected to severe amplitude harmonic excitation. In that study they observed that newly used modified TLD gives satisfactory results than the earlier used TLD models. The Lax finite difference method also consistently predicts numerical results that are closer to the experimental results than other methods for harmonic base motions. In this study a shallow water model of sloshing water has been considered to investigate response of the SDOF system subjected to different dynamic motions.

\section{Analytical formulation for TSWD}

\subsection{Shallow water wave theory}

This theory was first introduce in the coastal engineering. This theory defines the range of shallow water wave and which is $0.5<\mathrm{h} / \mathrm{L}<0.05-0.04$, where $\mathrm{L}$ is the length of the wave and $\mathrm{h}$ is the depth of the water. This ratio is generally kept in order to obtain as possible as high damping of sloshing.

\subsection{Fundamental sloshing frequency of the TSWD} 1992)

Estimation of the fundamental sloshing frequency of TSWD as per given equation (1) (L. F. Sun

$$
w_{l}=\frac{1}{2 \pi} \sqrt{\frac{\pi g}{2 a} \tanh \left(\frac{\pi h}{2 a}\right)}
$$

Where $\mathrm{g}=$ acceleration due to gravity. $\mathrm{h}=$ still water level

\subsection{Base shear due to sloshing of liquid}

The base shear force induced due to sloshing action of the liquid in the wall can be estimated by equation (2)

$$
F=\frac{\rho g b}{2}\left[\left(n_{n}+H\right)^{2}-\left(n_{0}+H\right)^{2}\right.
$$

Where $n n=$ free surface elevation of the right wall of the tank $\mathrm{n} 0=$ free surface elevation of the left wall of the tank $\mathrm{b}=$ width of a TSWD

$\mathrm{H}=\mathrm{a}$ mean liquid depth

This sloshing effect in rectangular tank is shown in Fig. 1. 


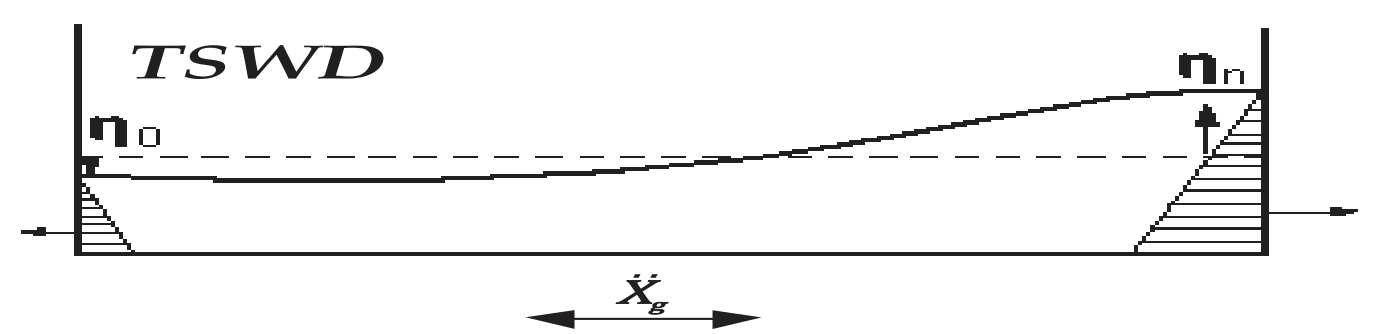

Fig. 1 sketch of action of liquid sloshing in rectangular tank

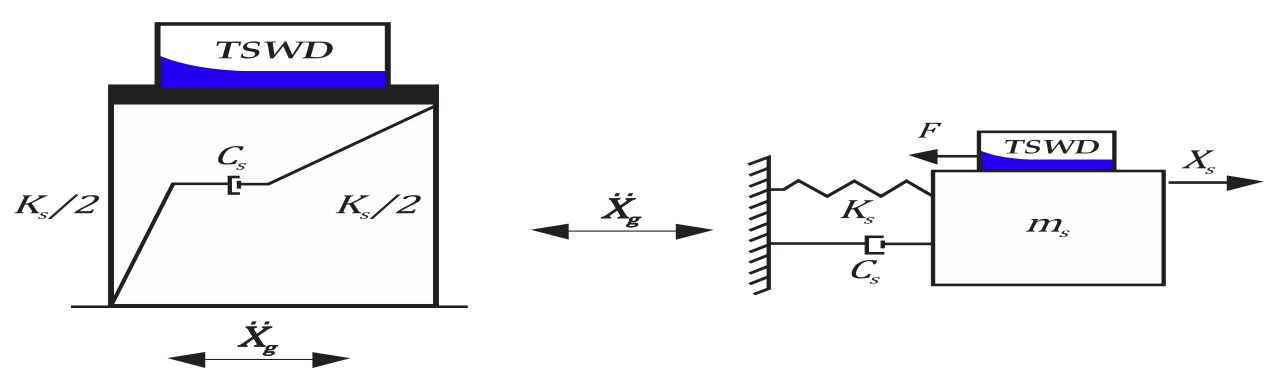

Fig. 2 structure-TSWD mathematical modelling

\subsection{Structure - TSWD Interaction}

The TSWD parameters such as frequency and damping ratio obtained from research approach for reducing the response effect.

A structure of SDOF system is considered to be converted into two degree of freedom due to attachment of TSWD as shown in Fig. 2.

The equation of motion for two degree of freedom is:

$$
\left[\begin{array}{cc}
m_{d} & 0 \\
0 & m_{s}
\end{array}\right]\left\{\begin{array}{l}
\ddot{x}_{d} \\
\ddot{x}_{s}
\end{array}\right\}+\left[\begin{array}{cc}
c_{d} & -c_{d} \\
-c_{d} & c_{d}+c_{s}
\end{array}\right]\left\{\begin{array}{l}
\dot{x}_{d} \\
\dot{x}_{s}
\end{array}\right\}+\left[\begin{array}{cc}
k_{d} & -k_{d} \\
-k_{d} & k_{d}+k_{s}
\end{array}\right]\left\{\begin{array}{l}
x_{d} \\
x_{s}
\end{array}\right\}=\left\{\begin{array}{l}
0 \\
f
\end{array}\right\}
$$

\subsection{Parameters of TSWD}

The behavior of the SDOF system equipped with TSWD subjected to base excitation will depends on the features of the SDOF-TSWD system.

1. Depth ratio $(\Delta=h / l)$

It is the ratio of the depth of water (h) to the length of the tank is an important parameter for identifying the effectiveness of rectangular TSWD.

According to Rao at al. Different depth ratio varying from 0.05 to 0.3 . They detected that exists and optimum depth ratio 0.125 is responsible for the minimum response amplitude.

2. Frequency ratio $\left(\beta=f / f_{s}\right)$

The frequency ratio is the ratio of TSWD damper frequency to the natural frequency of the structure. Rao at al. Kept frequency ratio from 0.5 to 1.5 . And they observed that in earlier stage when excitation frequency lesser than the resonant frequency, the minimum structural response increased and amplitude according to response reduces extremely by attachment of TSWD.

3. Mass ratio $\left(\mu=m_{w} / m_{s}\right)$

It is the ratio of water mass to the structural mass, it plays important role in the TSWD design. 
Rao at al., studied the TSWD efficiency under different ranges of mass ratios has been investigated in terms of structural displacement reduction.

In that different mass ratio has been used in the range of $0.5 \%$ to $6 \%$ and the excitation frequency is equal to the resonance of the structure.

They concluded that up to $3 \%$ to $4 \%$ mass ratio is more effective for reduction of response.

\section{Numerical Study}

\subsection{Analysis of SDOF structure}

In this paper Newmark's gamma-beta average acceleration method is used. Response is carried out using MATLAB. In which gamma and beta is taken as $0.5 \& 0.25$ respectively. Time period of considered structure is $1 \mathrm{sec}$, Frequency ratio is taken as 1.

In this numerical study a SDOF system is considered upon which water sloshing damper attached. Hence it is converted into two degree of freedom structure. And it is analyzed through a MATLAB.

\section{Result and discussion}

The numerical study have been carried out by applying various time history. For each time history total acceleration is generated. In this study the maximum acceleration response spectrum of SDOF system for the different time history considered which is shown in Fig. 3.

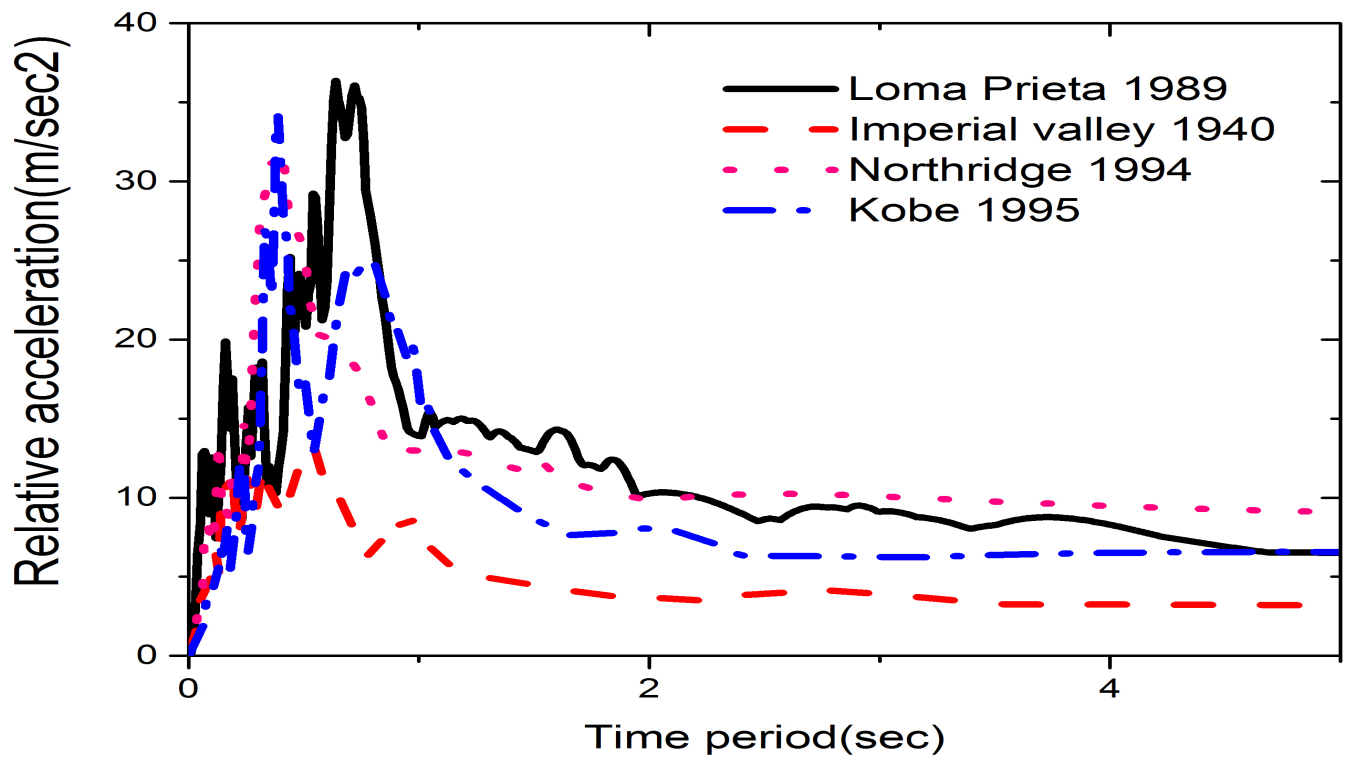

Fig.3 Maximum acceleration spectra for $2 \%$ damping for various time history used for SDOF structure.

Here acceleration response of various time history for the SDOF system is used when the structurewater sloshing damper system is experienced to a particular base excitation, is determined using 
numerical formulation by Newmark's beta method and the response of SDOF structure is shown in Fig. 4. Fig. 5 \& 6 represents comparison of the responses considering different earthquakes for various mass ratios as referenced in table $1,2,3 \& 4$.
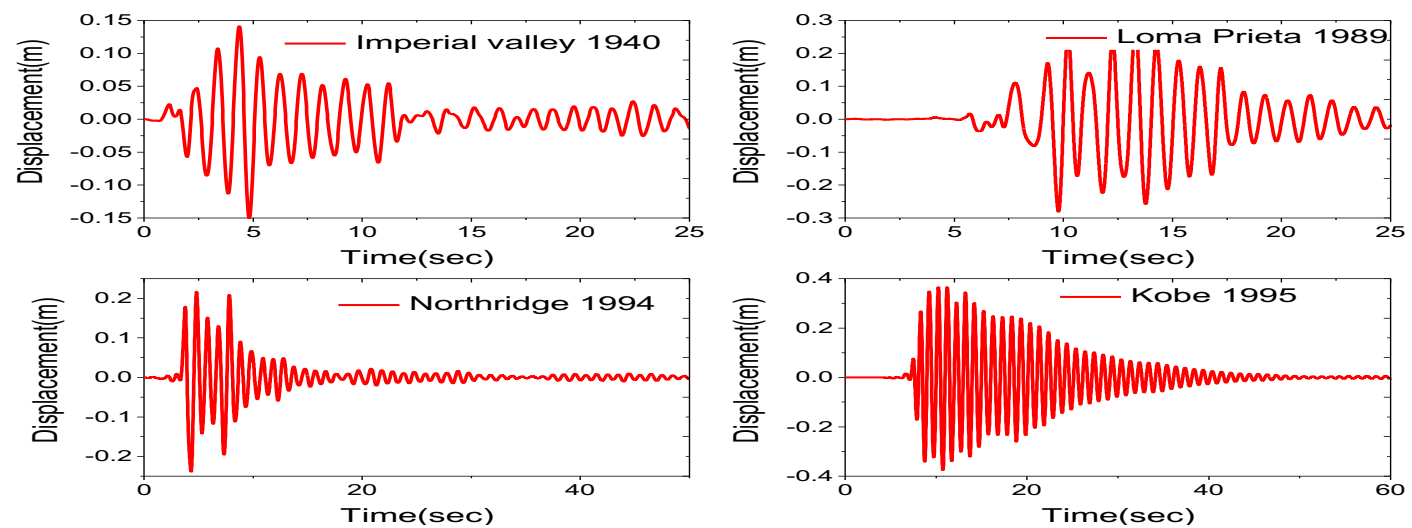

Fig. 4 Typical numerical structural Displacement response for different time history

In the figure $5 \&$ figure 6 , it is clearly showed that the effectiveness of a perfectly design water sloshing damper used as a structural response reducer for the SDOF system which was reduced response of the system drastically. Where a comparison of typical measured acceleration response time histories for the SDOF structure with and without water sloshing damper is shown. In these comparison mass ratio is taken $0.5 \%$ and $1 \%$.
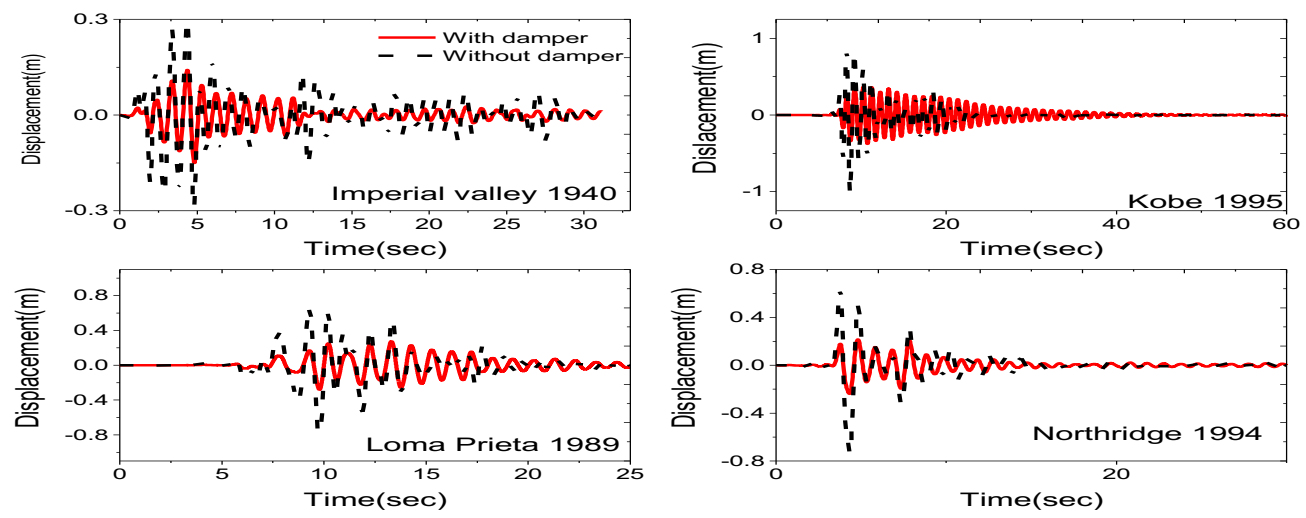

Fig. 5 Normal measured structural displacement time histories for a mass ratio is $0.5 \%$ 

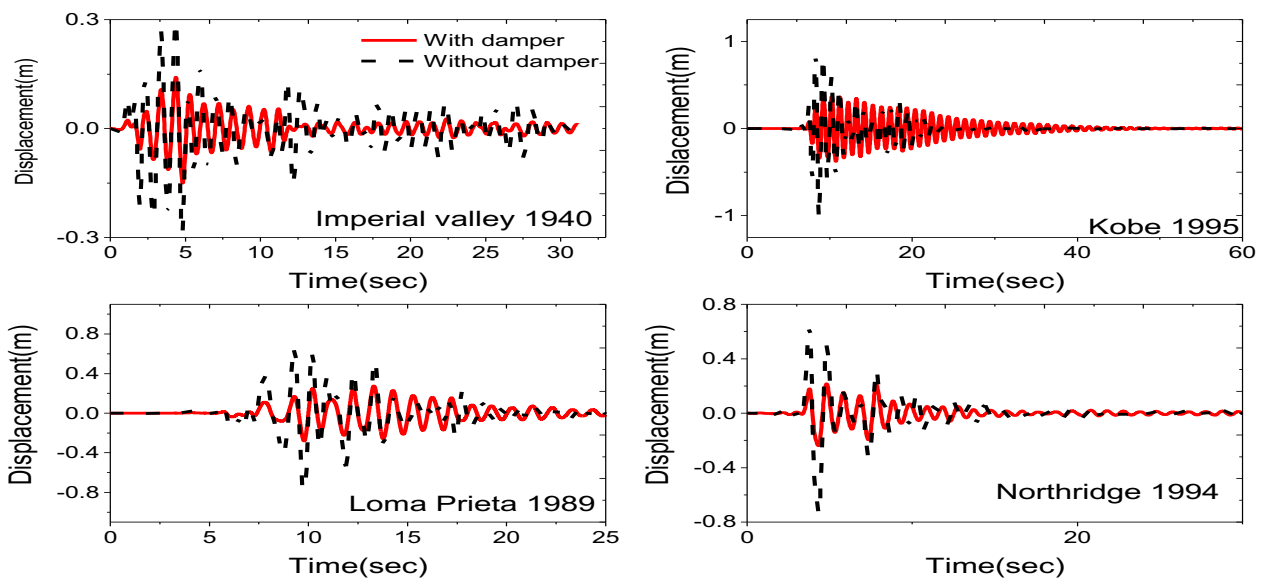

Fig. 6 Normal measured structural displacement time histories for a mass ratio is $1 \%$

The past study, showed that there are water sloshing damper parameters, the mass ratio gives the effectiveness of a TLD for the severe amplitude motion. Various mass ratio from $0.5 \%$ to $6 \%$ have been considered in this numerical process. (See table 1, 2, 3, 4).

The variation of the mass ratio showed that reduction of the response of the system equipped with water sloshing damper. Structural response reduced by increasing mass ratio. The reduction in structural response for a mass ratio up to $4 \%$ is considerable. After that response is increased.

Loma Prieta (1989)

\begin{tabular}{|r|r|r|r|r|r|r|}
\hline \multirow{2}{*}{\begin{tabular}{c}
\multirow{2}{*}{$\begin{array}{c}\text { Mass } \\
\text { ratio }\end{array}$} \\
\cline { 2 - 7 }
\end{tabular}} & $\begin{array}{c}\text { without } \\
\text { damper }\end{array}$ & $\begin{array}{c}\text { with } \\
\text { damper }\end{array}$ & $\begin{array}{c}\text { \% } \\
\text { Reduction }\end{array}$ & $\begin{array}{c}\text { without } \\
\text { damper }\end{array}$ & $\begin{array}{c}\text { Acceleration(mith } \\
\text { damper }\end{array}$ & $\begin{array}{c}\text { \% } \\
\text { Reduction }\end{array}$ \\
\hline 0.005 & 0.2601 & 0.26 & 0.24 & 10.332 & 10.36 & 0.27 \\
\hline 0.01 & 0.2601 & 0.26 & 0.37 & 10.332 & 10.38 & 0.41 \\
\hline 0.015 & 0.2601 & 0.26 & 0.39 & 10.332 & 10.38 & 0.47 \\
\hline 0.02 & 0.2601 & 0.26 & 0.30 & 10.332 & 10.38 & 0.43 \\
\hline 0.025 & 0.2601 & 0.26 & 0.12 & 10.332 & 10.36 & 0.28 \\
\hline 0.03 & 0.2601 & 0.26 & 0.15 & 10.332 & 10.34 & 0.04 \\
\hline 0.035 & 0.2601 & 0.26 & 0.51 & 10.332 & 10.30 & 0.29 \\
\hline 0.04 & 0.2601 & 0.26 & 0.95 & 10.332 & 10.26 & 0.68 \\
\hline 0.045 & 0.2601 & 0.26 & 1.47 & 10.332 & 10.22 & 1.13 \\
\hline 0.05 & 0.2601 & 0.25 & 2.06 & 10.332 & 10.16 & 1.66 \\
\hline 0.055 & 0.2601 & 0.25 & 2.73 & 10.332 & 10.10 & 2.25 \\
\hline 0.06 & 0.2601 & 0.25 & 3.46 & 10.332 & 10.04 & 2.91 \\
\hline
\end{tabular}

Table 1 Peak relative displacement and acceleration of the structure for Loma Prieta (1989) 
Imperial Valley (1940)

\begin{tabular}{|c|c|c|c|c|c|c|}
\hline \multirow{2}{*}{$\begin{array}{l}\text { Mass } \\
\text { ratio }\end{array}$} & \multicolumn{3}{|c|}{ Displacement(m) } & \multicolumn{3}{|c|}{$\operatorname{Acceleration}(\mathrm{m} / \mathrm{sec} 2)$} \\
\hline & $\begin{array}{l}\text { without } \\
\text { damper }\end{array}$ & $\begin{array}{r}\text { with } \\
\text { damper }\end{array}$ & $\begin{array}{c}\% \% \\
\text { Reduction } \\
\end{array}$ & $\begin{array}{l}\text { without } \\
\text { damper }\end{array}$ & $\begin{array}{r}\text { with } \\
\text { damper }\end{array}$ & $\begin{array}{c}\% \% \\
\text { Reduction } \\
\end{array}$ \\
\hline 0.005 & 0.1123 & 0.10 & 8.29 & 4.4711 & 4.16 & 7.46 \\
\hline 0.01 & 0.1123 & 0.10 & 16.61 & 4.4711 & 3.89 & 15.00 \\
\hline 0.015 & 0.1123 & 0.09 & 24.47 & 4.4711 & 3.63 & 23.08 \\
\hline 0.02 & 0.1123 & 0.08 & 33.02 & 4.4711 & 3.39 & 31.92 \\
\hline 0.025 & 0.1123 & 0.08 & 42.38 & 4.4711 & 3.17 & 40.88 \\
\hline 0.03 & 0.1123 & 0.07 & 51.10 & 4.4711 & 3.01 & 48.35 \\
\hline 0.035 & 0.1123 & 0.07 & 56.18 & 4.4711 & 3.11 & 43.70 \\
\hline 0.04 & 0.1123 & 0.08 & 49.61 & 4.4711 & 3.30 & 35.35 \\
\hline 0.045 & 0.1123 & 0.08 & 42.04 & 4.4711 & 3.47 & 28.68 \\
\hline 0.05 & 0.1123 & 0.08 & 36.28 & 4.4711 & 3.63 & 23.31 \\
\hline 0.055 & 0.1123 & 0.09 & 31.37 & 4.4711 & 3.75 & 19.24 \\
\hline 0.06 & 0.1123 & 0.09 & 27.63 & 4.4711 & 3.85 & 16.18 \\
\hline
\end{tabular}

Table 2 Peak relative displacement and acceleration of the structure for Imperial Valley (1940)

Northridge (1995)

\begin{tabular}{|c|c|c|c|c|c|c|}
\hline \multirow{2}{*}{$\begin{array}{l}\text { Mass } \\
\text { ratio }\end{array}$} & \multicolumn{3}{|c|}{ Displacement(m) } & \multicolumn{3}{|c|}{$\operatorname{Acceleration}(\mathrm{m} / \mathrm{sec} 2)$} \\
\hline & $\begin{array}{l}\text { without } \\
\text { damper }\end{array}$ & $\begin{array}{r}\text { with } \\
\text { damper }\end{array}$ & $\begin{array}{c}\% \\
\text { Reduction }\end{array}$ & $\begin{array}{l}\text { without } \\
\text { damper }\end{array}$ & $\begin{array}{r}\text { with } \\
\text { damper }\end{array}$ & $\begin{array}{c}\text { \% } \\
\text { Reduction }\end{array}$ \\
\hline 0.005 & 0.2155 & 0.21 & 1.12 & 8.528 & 8.41 & 1.39 \\
\hline 0.01 & 0.2155 & 0.21 & 2.25 & 8.528 & 8.29 & 2.81 \\
\hline 0.015 & 0.2155 & 0.21 & 3.39 & 8.528 & 8.18 & 4.27 \\
\hline 0.02 & 0.2155 & 0.21 & 4.54 & 8.528 & 8.064 & 5.76 \\
\hline 0.025 & 0.2155 & 0.20 & 5.69 & 8.528 & 7.95 & 7.29 \\
\hline 0.03 & 0.2155 & 0.20 & 6.86 & 8.528 & 7.83 & 8.85 \\
\hline 0.035 & 0.2155 & 0.20 & 8.04 & 8.528 & 7.72 & 10.45 \\
\hline 0.04 & 0.2155 & 0.20 & 9.22 & 8.528 & 7.61 & 12.06 \\
\hline 0.045 & 0.2155 & 0.20 & 10.43 & 8.528 & 7.50 & 13.65 \\
\hline 0.05 & 0.2155 & 0.19 & 11.64 & 8.528 & 7.40 & 15.28 \\
\hline 0.055 & 0.2155 & 0.19 & 12.87 & 8.528 & 7.29 & 16.96 \\
\hline 0.06 & 0.2155 & 0.19 & 14.10 & 8.528 & 7.19 & 18.69 \\
\hline
\end{tabular}

Table 3 Peak relative displacement and acceleration of the structure for Northridge (1995) 
Kobe (1994)

\begin{tabular}{|c|c|c|c|c|c|c|}
\hline \multirow{2}{*}{$\begin{array}{l}\text { Mass } \\
\text { ratio }\end{array}$} & \multicolumn{3}{|c|}{ Displacement(m) } & \multicolumn{3}{|c|}{ Acceleration(m/sec2) } \\
\hline & $\begin{array}{l}\text { without } \\
\text { damper }\end{array}$ & $\begin{array}{r}\text { with } \\
\text { damper }\end{array}$ & $\begin{array}{c}\% \\
\text { Reduction }\end{array}$ & $\begin{array}{l}\text { without } \\
\text { damper }\end{array}$ & $\begin{array}{r}\text { with } \\
\text { damper }\end{array}$ & $\begin{array}{c}\% \\
\text { Reduction } \\
\end{array}$ \\
\hline 0.005 & 0.3023 & 0.30 & 1.12 & 12 & 11.96 & 0.33 \\
\hline 0.01 & 0.3023 & 0.30 & 2.28 & 12 & 11.92 & 0.61 \\
\hline 0.015 & 0.3023 & 0.29 & 3.48 & 12 & 11.88 & 0.94 \\
\hline 0.02 & 0.3023 & 0.29 & 4.73 & 12 & 11.84 & 1.32 \\
\hline 0.025 & 0.3023 & 0.29 & 6.03 & 12 & 11.79 & 1.75 \\
\hline 0.03 & 0.3023 & 0.28 & 7.37 & 12 & 11.76 & 2.02 \\
\hline 0.035 & 0.3023 & 0.28 & 8.62 & 12 & 11.74 & 2.17 \\
\hline 0.04 & 0.3023 & 0.28 & 9.79 & 12 & 11.72 & 2.37 \\
\hline 0.045 & 0.3023 & 0.27 & 10.99 & 12 & 11.69 & 2.61 \\
\hline 0.05 & 0.3023 & 0.27 & 12.23 & 12 & 11.66 & 2.90 \\
\hline 0.055 & 0.3023 & 0.27 & 13.52 & 12 & 11.62 & 3.21 \\
\hline 0.06 & 0.3023 & 0.26 & 14.84 & 12 & 11.62 & 3.22 \\
\hline
\end{tabular}

Table 4 Peak relative displacement and acceleration of the structure for Kobe(1994)

Above tables shows the real behavior of a water sloshing damper-structure system when system is subjected to past time history of ground motion. Here, this simulation is done by considering four recorded ground motions. As it has been shown in Banerji et al. investigation of water sloshing damperstructure system, by taking only one time history of ground motion made change in help to understand the behavior of the water sloshing damper structural system.

The response of a water sloshing damper-structure system for different time history is determined using the numerical procedure outlined earlier in this paper. The mean peak acceleration response and mean displacement response for each time history and the reduction in the response by a properly designed water sloshing damper is presented in above table. From above results conclusion is obtained that the properly designed water sloshing damper is quite effective in reduces the structural response under different type of the earthquake time history.

\section{Conclusion}

The outcome of this work is that, water sloshing damper is more cost effective control device currently available than others, water sloshing damper can be work effectively to reduce the response of the system subjected to severe amplitude ground excitation, by making proper design of it.

Following conclusion can be derived from the analysis as shown below.

1. The TSWD found to be effective for seismic response reduction of SDOF Structure.

2. There is variation in percentage reduction of response of structure for various TSWD parameters.

3. For the present study $4 \%$ mass ratio found to be effective for optimum acceleration response reduction. 


\section{ACKNOWLEDGEMENT}

The author deeply appreciate help and support provided by IE, India.

\section{References}

[1] Banerji, P., Murudi, M., Shah, A.H. and Popplewell, N. 2000. "Tuned liquid dampers for controlling earthquake response of structures." Earthquake Engineering and Structural Dynamics 587602 .

[2] Chaiseri, P., Fujino, Y., Pacheco, B.M. and Sun, L.M. (1989). 1989. "Interaction of tuned liquid damper and structure:theory, experimental verification and application." J. Structural Engg./Earthquake Engg. Proc. JSCE 273-282.

[3] Chavan, S.A., (2002). n.d. "Tuned liquid damper for structural control: experimental studies and numerical analysis." M. Tech Project, IIT Bombay.

[4] Fujino, Y., Sun, L.M., Pacheco, B.M. and Chaiseri, P. (1992). 1992. "Tuned liquid dampers (TLD) for suppressing horizontal motion of structures." Journal of Engineering Mechanics ASCE 20172030.

[5] Koh, C.G., Mahatma, S. and Wang, C.M. 1994. "Theoretical and experimental studies on rectangular tuned liquid dampers under arbitrary excitations. ." Earthquake Engineering and Structural Dynamics 17-31.

[6] Modi, V.J., Welt, F. and Irani, M.B. 1990. "On the suppression of vibrations using nutation dampers." Journal of Wind Engineering and Industrial Aerodynamics 273-282.

[7] Nishant Kishore Rai, G. R. Reddy and V. Venkatraj. 2013. "Tuned Liquid Sloshing Water Damper: A Robust Device for Seismic Retrofitting." International Journal of Environmental Science: Development and Monitoring (IJESDM).

[8] Samanta, A. and Banerji, P. 2006. "Efficient numerical schemes to analyse earthquake response of structures with tuned liquid dampers." 13th Symposium on Earthquake Engineering Indian Institute of Technology Roorkee 1372-1381.

[9] Sun, L.M., Fujino, Y. and Koga, K. 1995. "A model of tuned liquid damper for suppressing pitching motions of structures." Earthquake Engineering and Structural Dynamics 625-636.

[10] Sun, L.M., Fujino, Y., Pacheco, B.M. and Chaiseri, P. 1992. "Modelling of Tuned Liquid Damper (TLD)." Journal of Wind Engineering and Industrial Aerodynamic 1883-1894.

[11] Tamura, Y., Fujii, K., Ohtsuki, T., Wakahara, T. and Kohsaka, R. 1995. "Effectiveness of tuned liquid dampers under wind excitations. ." Engineering and Structure 609-621.

[12] Venkateswara Rao K, Dr. K. C. Biswal. N.D. "Experimantal And Numerical Studies On Tuned Liquid Damper." 